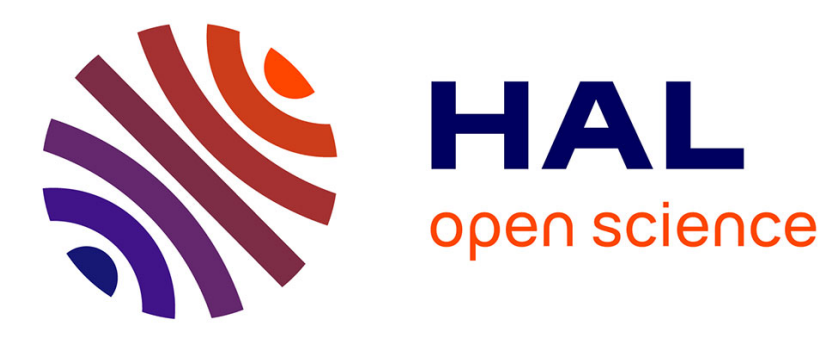

\title{
The 76-gene signature defines high-risk patients that benefit from adjuvant tamoxifen therapy
}

\author{
Yi Zhang, Anieta M. Sieuwerts, Michelle Mcgreevy, Graham Casey, Tanja \\ Cufer, Angelo Paradiso, Nadia Harbeck, Paul N. Span, David G. Hicks, \\ Joseph Crowe, et al.
}

\section{To cite this version:}

Yi Zhang, Anieta M. Sieuwerts, Michelle Mcgreevy, Graham Casey, Tanja Cufer, et al.. The 76-gene signature defines high-risk patients that benefit from adjuvant tamoxifen therapy. Breast Cancer Research and Treatment, 2008, 116 (2), pp.303-309. 10.1007/s10549-008-0183-2 . hal-00478265

\section{HAL Id: hal-00478265 https://hal.science/hal-00478265}

Submitted on 30 Apr 2010

HAL is a multi-disciplinary open access archive for the deposit and dissemination of scientific research documents, whether they are published or not. The documents may come from teaching and research institutions in France or abroad, or from public or private research centers.
L'archive ouverte pluridisciplinaire HAL, est destinée au dépôt et à la diffusion de documents scientifiques de niveau recherche, publiés ou non, émanant des établissements d'enseignement et de recherche français ou étrangers, des laboratoires publics ou privés. 


\title{
The 76-gene signature defines high-risk patients that benefit from adjuvant tamoxifen therapy
}

\author{
Yi Zhang · Anieta M. Sieuwerts · Michelle McGreevy • Graham Casey • \\ Tanja Cufer · Angelo Paradiso $\cdot$ Nadia Harbeck · Paul N. Span • \\ David G. Hicks · Joseph Crowe · Raymond R. Tubbs · G. Thomas Budd • \\ Joanne Lyons · Fred C. G. J. Sweep • Manfred Schmitt · Francesco Schittulli • \\ Rastko Golouh $\cdot$ Dmitri Talantov $\cdot$ Yixin Wang $\cdot$ John A. Foekens
}

Received: 28 August 2008/Accepted: 2 September 2008/Published online: 23 September 2008

(C) Springer Science+Business Media, LLC. 2008

\begin{abstract}
Purpose To assess the benefit from adjuvant systemic tamoxifen therapy in breast cancer risk groups identified by the previously established prognostic 76-gene signature. Methods In 300 lymph node-negative $(\mathrm{LNN})$, estrogen receptor-positive (ER+) breast cancer patients (136 treated with adjuvant tamoxifen, 164 having received no systemic adjuvant therapy), distant metastasis-free survival (DMFS) as a function of the 76-gene signature was determined in a multicenter fashion. Results In 136 tamoxifen-treated patients, the 76-gene signature identified a group of patients with a poor prognosis [hazard ratio (HR), 4.62; $P=0.0248$ ]. These patients showed a $12.3 \%$ absolute benefit of tamoxifen in 10-year
\end{abstract}

Y. Zhang $\cdot$ D. Talantov $\cdot$ Y. Wang

Veridex LLC, Johnson \& Johnson Company, San Diego, CA, USA

A. M. Sieuwerts · J. A. Foekens $(\bowtie)$

Department of Medical Oncology, Erasmus Medical

Center-Josephine Nefkens Institute and Cancer Genomics

Centre, Room BE-426, Rotterdam, The Netherlands

e-mail: j.foekens@erasmusmc.nl

M. McGreevy

Department of Cancer Biology, Cancer Clinic Foundation,

Cleveland, $\mathrm{OH}$, USA

G. Casey

Department of Preventive Medicine, University of Southern

California, Los Angeles, CA, USA

T. Cufer $\cdot$ R. Golouh

Institute of Oncology, Ljubljana, Slovenia

A. Paradiso - F. Schittulli

National Cancer Institute, Bari, Italy
DMFS (HR, 0.52; $P=0.0318)$ compared with untreated high-risk patients. This represented a $71 \%$ increase in relative benefit compared with the $7.2 \%$ absolute benefit observed for all 300 patients without using the gene signature. In the low-risk group there was no significant 10-year DMFS benefit of tamoxifen. Conclusions The 76-gene signature defines high-risk patients who benefit from adjuvant tamoxifen therapy. Although we did not study the value of chemotherapy in this study, low-risk patients identified by the 76-gene signature have a prognosis good enough that chemotherapy would be difficult to justify. The prognosis of these patients is sufficiently good, in fact, that a disease-free benefit for tamoxifen

N. Harbeck - M. Schmitt

Department of Obstetrics and Gynecology, Klinikum rechts der Isar, Technische Universitaet Muenchen, Munich, Germany

P. N. Span · F. C. G. J. Sweep

Department of Chemical Endocrinology, Radboud University Nijmegen Medical Centre, Nijmegen, The Netherlands

D. G. Hicks

Department of Pathology, University of Rochester Medical Center, Rochester, NY, USA

J. Crowe $\cdot$ J. Lyons

Department of Breast Services, Cleveland Clinic Foundation, Cleveland, $\mathrm{OH}$, USA

R. R. Tubbs

Department of Molecular Pathology, Cleveland Clinic

Foundation, Cleveland, OH, USA

G. T. Budd

Department of Solid Tumor Oncology, Cleveland Clinic

Foundation, Cleveland, OH, USA 
therapy is difficult to prove, though benefits in terms of loco-regional relapse and a reduction in risk for contralateral breast cancer might justify hormonal therapy in these patients.

Keywords Breast cancer - Gene signature - Prognosis Tamoxifen benefit

\section{Introduction}

Breast cancers are classified as steroid hormone receptorpositive or -negative tumors to decide on adjuvant endocrine therapy because only estrogen receptor (ER)- and/or progesterone receptor (PR)-positive tumors are thought to be responsive to selective estrogen receptor modulators like tamoxifen [1]. Adjuvant endocrine therapy accounts for almost two-thirds of the overall benefit of adjuvant therapy in patients with hormone receptor-positive breast cancer. However, a significant proportion of ER-positive tumors exhibit resistance to endocrine therapy. Clinical studies in lymph node-negative (LNN)/ER + patients show that the absolute distant disease-free survival benefit of tamoxifen therapy is only about $9 \%$, with a relative benefit of about $30 \%$ [2, 3]. These benefits from treatment may, however, differ substantially according to, e.g., patient's age and the tumor level of ER [2] and it is therefore of importance to identify biomarkers that allow identification of those breast cancer patients who may actually benefit from adjuvant tamoxifen.

Microarray technologies profiling the entire human genome have successfully been used to classify breast tumors into clinically relevant subtypes [4-7] and to build gene signatures to predict cancer metastasis [8-11] and treatment response [12-14]. From a clinical point of view, it is of vital importance that the predicted risk groups have differential survival benefits by adjuvant systemic therapy in order to guide treatment decision-making. For example, the 21-gene oncotype DX test, which defines different prognostic risk groups in LNN ER-positive patients treated with adjuvant tamoxifen [15], has revealed the benefit of chemotherapy in patients who were classified high-risk by the test [16]. However, there are no publications yet on any of the prognostic signatures identified so far to provide such information as to tamoxifen treatment.

We previously established and validated, both in singlecenter and multi-center studies, a 76-gene prognostic signature for prediction of distant metastasis in breast cancer patients $[9,17,18]$. In the present study, we investigated whether the 76-gene signature predicts survival and benefit from adjuvant endocrine therapy in LNN ER-positive patients who received adjuvant systemic therapy with tamoxifen alone.

\section{Patients and methods}

\section{Patients}

Frozen tumor specimens, clinical information and microarray data for breast cancer patients having received neither neoadjuvant nor adjuvant systemic therapy, were described previously [17]. Of the 180 patients, 164 with ER-positive tumors were included in the present study. For patients treated with adjuvant tamoxifen, frozen tumor specimens were selected from the tumor banks in three of the four European institutions that provided the samples of patients without systemic therapy, i.e., Institute of Oncology, Ljubljana, Slovenia (36 samples; 1997-1999), National Cancer Institute, Bari, Italy (28 samples; 1990-1998), and Technische Universitaet Muenchen, Germany (9 samples; 1992-1999), and from one US institution, Cleveland Clinic Foundation (63 samples; 1981-2000). The distant metastasis-free survival (DMFS) among patients from different institutions was not different $(\log \operatorname{rank} P=0.63)$. All samples were drawn from the consecutive series of patients available in the institutions within the respective periods based on pre-defined inclusion criteria: histological diagnosis of LNN breast cancer, ER-positive primary tumor, adjuvant tamoxifen treatment, informed consent and/or approval by a local Ethical Committee, at least 5 years of follow-up except for patients who developed distant relapse within 5 years, no signs of disease within 1 month after primary surgery, and frozen tissue should be available. Exclusion criteria were: neoadjuvant or adjuvant chemotherapy, history of other primary cancer (except for basal cell carcinoma), less than 50\% tumor area on hematoxylin/eosin (HE) section at time of extraction of RNA, or poor RNA quality. ER status was determined by immunohistochemical or biochemical assay, with $10 \%$ positive tumor cells or $10 \mathrm{fmol} / \mathrm{mg}$ cytosolic protein used as cutoff, respectively. In the present study, the reporting recommendations for tumor marker prognostic studies (REMARK [19]) were adhered to where ever applicable. Patient and tumor characteristics are summarized in Table 1. Adjuvant tamoxifen therapy was administered according to national guidelines at the time. Routine postsurgical follow-up was similar among the participating institutions and involved examination every 3 months during the first 2 years, every 6 months for years $2-5$, and annually from year 5 of the follow-up period. Date of diagnosis of metastasis was defined as the date of imaging or histological confirmation of metastasis after complaints and/or clinical symptoms, or at regular follow-up. The surviving patients $(n=119)$ had a median follow-up time of 90 months (range 29-193 months). Twenty (15\%) patients showed evidence of distant metastases with 12 (9\%) having metastases within 5 years. A total of 17 
Table 1 Patient and tumor characteristics

\begin{tabular}{|c|c|c|c|}
\hline Characteristics & $\begin{array}{l}\text { Untreated } \\
(n=164)\end{array}$ & $\begin{array}{l}\text { Tamoxifen-treated } \\
(n=136)\end{array}$ & $\begin{array}{l}\text { Chi-square } \\
P \text {-value }\end{array}$ \\
\hline \multicolumn{4}{|l|}{ Age (years) } \\
\hline Mean (SD) & $57(11)$ & $64(9)$ & \multirow[t]{6}{*}{$<0.0001$} \\
\hline$\leq 40$ & $12(7 \%)$ & $4(3 \%)$ & \\
\hline $41-55$ & $63(39 \%)$ & $23(17 \%)$ & \\
\hline $56-70$ & $68(41 \%)$ & $80(59 \%)$ & \\
\hline$>70$ & $20(12 \%)$ & $29(21 \%)$ & \\
\hline Unknown & $1(1 \%)$ & 0 & \\
\hline \multicolumn{4}{|l|}{ T stage } \\
\hline $\mathrm{T} 1$ & $88(54 \%)$ & $63(46 \%)$ & \multirow[t]{4}{*}{0.0600} \\
\hline $\mathrm{T} 2$ & $75(45 \%)$ & $65(48 \%)$ & \\
\hline $\mathrm{T} 3 / 4$ & $1(1 \%)$ & $7(5 \%)$ & \\
\hline Unknown & 0 & $1(1 \%)$ & \\
\hline \multicolumn{4}{|l|}{ Tumor grade } \\
\hline Poor & $48(29 \%)$ & $30(22 \%)$ & \multirow[t]{4}{*}{0.9312} \\
\hline Moderate & $77(47 \%)$ & $43(32 \%)$ & \\
\hline Good & $14(9 \%)$ & $8(6 \%)$ & \\
\hline Unknown & $25(15 \%)$ & $55(40 \%)$ & \\
\hline \multicolumn{4}{|c|}{ Metastasis within 5 years } \\
\hline Yes & $29(18 \%)$ & $12(9 \%)$ & \multirow[t]{2}{*}{0.0399} \\
\hline No & $135(82 \%)$ & $124(91 \%)$ & \\
\hline \multicolumn{4}{|c|}{ Predicted risk group } \\
\hline High-risk & $95(58 \%)$ & $89(65 \%)$ & \multirow[t]{2}{*}{0.2257} \\
\hline Low-risk & $69(42 \%)$ & $47(35 \%)$ & \\
\hline
\end{tabular}

patients died, with 6 dying without evidence of metastasis. These patients were censored at last follow-up in the analysis of DMFS.

\section{Gene expression analysis}

Total RNA was extracted from tumor tissues (median $90 \mathrm{mg}$; range 40-120 mg) at the Erasmus MC, Rotterdam, as described before [9] and at Cleveland Clinic Foundation, Cleveland, and was sent to Veridex LLC, San Diego, for further analysis. The median RNA yield was $82 \mu \mathrm{g}$ (range 19-240 $\mu \mathrm{g}$ ). RNA quality was checked by use of the Agilent BioAnalyzer, and samples were profiled only if they had clear distinct $18 \mathrm{~S}$ and $28 \mathrm{~S}$ peaks with no minor peaks present, the area under the $18 \mathrm{~S}$ and $28 \mathrm{~S}$ peaks was more than $15 \%$ of the total RNA area, and if the $28 \mathrm{~S} / 18 \mathrm{~S}$ ratio was between 1.2 and 2.0. Biotinylated targets were prepared using published methods (Affymetrix, CA) [20] and hybridized to Affymetrix U133A GeneChips (Affymetrix, CA). Chips with average intensity of less than 40 or background signal of more than 100 were excluded. Each probe set was considered as a separate gene. Expression values for each gene were calculated using Affymetrix GeneChip analysis software MAS 5.0. For scaling, probe sets were scaled to a target intensity of 600 and scale mask filters were not selected.

\section{Statistical methods}

Based on our previous validation studies [17, 18] that reported hazard ratios (HRs) $>5$, and to achieve $80 \%$ power at a 0.05 significance level, we required at least 15 distant metastases and 60 non-metastases (assuming 20\% prevalence) in the present study. A total of 300 samples met our inclusion criteria, thus 164 patients without adjuvant systemic treatment and 136 samples with tamoxifen therapy, which were included in this study.

The microarray data were nonlinearly normalized, using a cubic B-spline smoother, to ensure the same signal intensity distribution as the original discovery dataset used to establish the 76-gene signature [9].

The disease relapse score was computed to classify each patient into either high- or low-risk for developing distant metastasis, as described previously [9]. Since all patients had ER-positive tumors, of the 76-gene signature only the 60 genes relevant for ER-positive tumors were used in the present calculation. Briefly, the calculation of the disease relapse score was as follows:

Relapse score $=313.5 I+\sum_{i=1}^{60} I w_{i} x_{i}$

where $w_{i}$ is the standardized Cox regression coefficient for the 60 genes and $x_{i}$ is the expression value of the 60 genes in $\log 2$ scale.

Patients with a disease relapse score $>0$ were classified high-risk (poor 76-gene signature), those with a disease relapse score $<0$ low-risk (good 76-gene signature). Kaplan-Meier survival plots [21] and log rank tests were used to assess differences in DMFS of the predicted high- and low-risk groups.

Univariate Cox's proportional-hazard regression models were used to calculate HRs to quantify relative risk of distant metastasis in the high-risk group compared with that in the low-risk group predicted by the gene signature, as well as the relative risk of distant metastasis in the untreated patient compared with that in tamoxifen-treated patients for each of the risk groups predicted by the 76-gene signature. The multivariate Cox proportional-hazard regression model was used to compare the prognostic strength of the 76-gene signature with those of the traditional prognostic factors. The likelihood ratio test using a full model based on a natural cubic spline was used to check for the non-linearity of the disease relapse scores as the predictor in Cox models. All statistical analyses were performed using $\mathrm{R}$ version 2.6.2. The dataset has been submitted to the NCBI/Genbank GEO database (series entry GSE12093). 


\section{Results}

Patient and tumor characteristics

A total of 300 ER-positive tumors were included in this study. One-hundred and sixty-four samples were from our previous multicenter validation study [17], which only included patients who received neither neoadjuvant nor adjuvant systemic therapy. The other 136 tumors included in the present study were from patients who had received adjuvant tamoxifen therapy only. The treated and untreated cohorts were similar with respect to patient and tumor characteristics except that the untreated patients were younger than the tamoxifen-treated patients (Table 1). The tamoxifen-treated patients had a significantly lower rate of distant metastasis than the untreated patients, possibly due to the effect of therapy. However, caution should be taken to decisively interpret these results as an effect of tamoxifen therapy because the included patients did not participate in a randomized trial, but received local treatment according to institutional guidelines effective at the time of surgery. The 76-gene signature classified 184 $(61 \%)$ patients high-risk and $116(36 \%)$ patients low-risk. The ratio of predicted high-risk versus low-risk patients was not different in the two cohorts (Table 1).

Ten-year DMFS benefit of tamoxifen therapy in the predicted risk groups

The 76-gene signature, when applied to the 136 tamoxifentreated patients, stratified the tamoxifen-treated cohort into high-risk and low-risk groups $(\mathrm{HR}=4.62$, log rank $P=0.0248$, Fig. 1a). The 10-year DMFS of the low-risk group identified by the 76-gene signature was $96 \%$ compared with $77 \%$ for the high-risk group. The predicted high-risk group showed a better survival outcome than those of the previously reported validation studies that included only patients who did not receive any adjuvant systemic therapy $[9,17,18]$. This might be a result of the improvement of survival from the tamoxifen treatment. As a matter of fact, the 136 tamoxifen-treated patients did have a non-significant (7.2\%) better 10-year DMFS than the 164 untreated patients $(\mathrm{HR}=0.61, \quad \log$ rank $P=0.0890$, Fig. 1b). In Cox multivariate regression analysis for DMFS in all patients, including patient's age, tumor size and grade, and tamoxifen use, the 76-gene signature was an independent prognostic variable with a HR of 6.13 (Table 2).

When we applied the 76-gene signature to the complete cohort of 300 patients, the low-risk group of 116 patients predicted by the signature showed a $2.7 \%$ non-significant 10-year DMFS benefit of tamoxifen ( HR $=0.73$, Fig. $2 \mathrm{a})$. The predicted high-risk group of 184 patients identified by

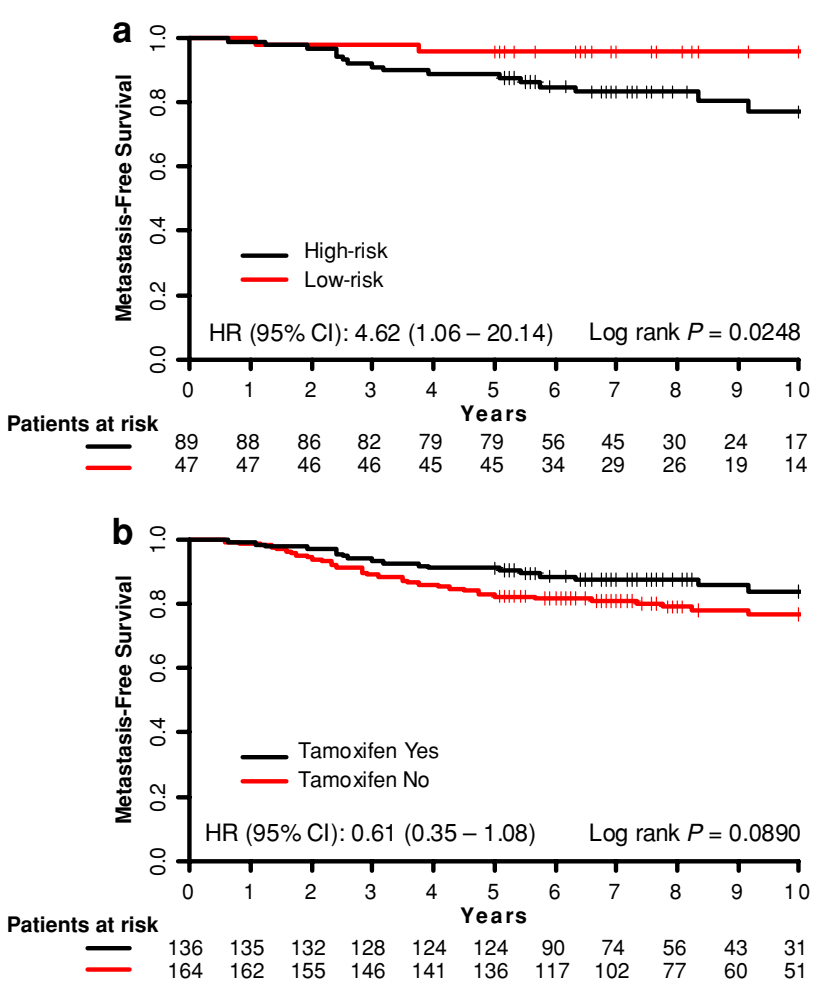

Fig. 1 Kaplan-Meier analysis of DMFS for validation of the 76-gene signature in tamoxifen-treated patient cohort and for assessing the DMFS benefit by tamoxifen treatment. (a) Validation of the 76-gene signature in tamoxifen-treated patients, (b) Comparison of DMFS in patients treated with adjuvant tamoxifen therapy and not. Patients at risk at 1 year time intervals are indicated

the 76-gene signature, however, showed a significant 10-year DMFS absolute benefit of $12.3 \%$ with tamoxifen therapy ( $\mathrm{HR}=0.52$, log $\operatorname{rank} P=0.0318)$. In this predicted high-risk group the 10-year DMFS for untreated and tamoxifen-treated patients was 64.7 and $77.0 \%$, respectively (Fig. 2b). This represents a $71 \%$ increase in benefit

Table 2 Multivariate Cox regression analysis for 10-year DMFS

\begin{tabular}{|c|c|c|c|}
\hline \multirow[t]{2}{*}{ Variable } & \multicolumn{3}{|c|}{ Multivariate analysis ${ }^{\mathrm{a}}$} \\
\hline & $\mathrm{HR}^{\mathrm{b}}$ & $(95 \% \mathrm{CI})$ & $P$-value \\
\hline Age (per 10-year increment) ${ }^{b}$ & 0.89 & $(0.67-1.17)$ & 0.3964 \\
\hline Tumor size ${ }^{\mathrm{c}}$ & 1.25 & $(0.67-2.34)$ & 0.4902 \\
\hline Grade $^{\mathrm{d}}$ & 1.05 & $(0.56-1.98)$ & 0.8634 \\
\hline Tamoxifen use $\mathrm{e}^{\mathrm{e}}$ & 0.46 & $(0.25-1.10)$ & 0.0856 \\
\hline Gene signature $^{f}$ & 6.13 & $(2.44-26.3)$ & 0.0006 \\
\hline \multicolumn{4}{|c|}{$\begin{array}{l}\text { Total } 219 \text { testing set patients evaluated, } 81 \text { patients excluded due to } \\
\text { missing values }\end{array}$} \\
\hline \multicolumn{4}{|l|}{ b Hazard ratio } \\
\hline \multicolumn{4}{|c|}{ c Tumor size: ">20 mm" versus " $=<20 \mathrm{~mm} "$} \\
\hline \multicolumn{4}{|c|}{ d Grade: "moderate \& well" versus "poor" } \\
\hline \multicolumn{4}{|c|}{ e Tamoxifen use: "yes" versus "no" } \\
\hline \multicolumn{4}{|c|}{ f Gene signature: "high-risk" versus "low-risk" } \\
\hline
\end{tabular}




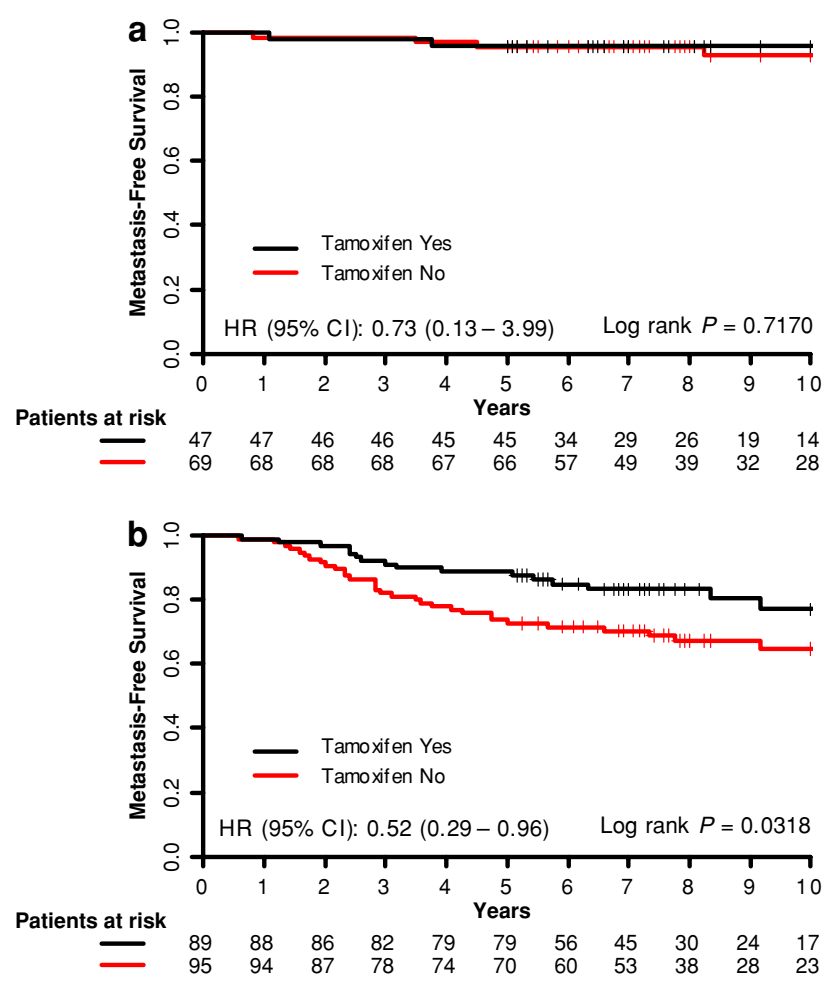

Fig. 2 Kaplan-Meier analysis of DMFS as a function of tamoxifen treatment in different risk groups of patients. (a) Low-risk patients predicted by the 76-gene signature, (b) High-risk patients predicted by the 76 -gene signature. Patients at risk at 1 year time intervals are indicated

compared with the $7.2 \%$ absolute 10-year DMFS benefit for all patients without using the signature (Fig. 1b).

Relationship of the disease relapse score and the magnitude of tamoxifen benefit

A Cox proportional regression model was applied to calculate the relationship of probability of distant metastasis at 10 years with the disease relapse score. The likelihood ratio test for non-linearity indicated that a linear fit of the disease relapse score was sufficient $(P=0.52)$. It appeared that the magnitude of tamoxifen benefit increased as the disease relapse score increased and reached the maximum benefit at the score of 125 (Fig. 3).

\section{Discussion}

In analogy with previous studies including only patients who did not receive adjuvant systemic therapy, showing a strong prognostic power of the 76-gene signature with HRs for DMFS ranging from 5.67 to $7.41[9,17,18]$, the present study shows that in patients who received adjuvant tamoxifen therapy the 76-gene signature was able to identify a high-risk group with a poor prognosis $(\mathrm{HR}=4.62)$. The

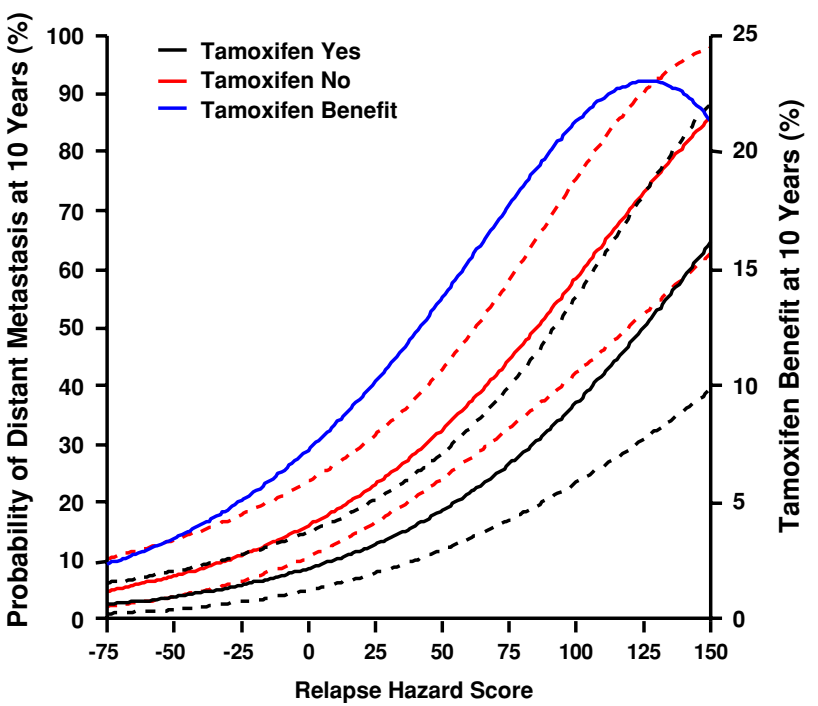

Fig. 3 Relationship of probability of distant metastasis at 10 years (and the 95\% confidence intervals, dotted lines), as well as the difference in probability of distant metastasis at 10 years, and the disease relapse score for untreated and tamoxifen-treated patients

10-year DMFS of the low-risk group identified by the 76 -gene signature was $19 \%$ better compared with that for the high-risk group. The excellent prognosis of tamoxifentreated (mainly postmenopausal) patients with a favorable 76-gene signature $(96 \%$ distant metastasis free after 10 years) would imply that $\mathrm{LNN} / \mathrm{ER}+$ patients do not need additional aggressive adjuvant chemotherapy, or incorporation of more expensive adjuvant endocrine options (e.g., aromatase inhibitors), if postmenopausal.

Among the genomic studies to define signatures for responsiveness to endocrine therapy, commonly both treated and untreated patient groups are not simultaneously included [10, 12, 15, 22, 23]. Based on the results observed in the 136 tamoxifen-treated patients only, no conclusion can be drawn on whether the 76-gene signature is a prognostic factor, a predictive factor, or both. A prognostic factor is not necessarily also a predictive factor, or vice versa [24]. To address the question of whether the 76-gene signature may not only be a prognostic signature as determined before $[9,17,18]$, but may also be predictive for outcome on tamoxifen therapy, in the present study we have included an untreated control group. The control group consisted of the $164 \mathrm{LNN} / \mathrm{ER}+$ tumors from our previously untreated multicentric cohort [17] from the same European institutions that provided the tamoxifen-treated samples for the present study. One should keep in mind that to determine predictive information, a properly designed prospective study should ideally be performed. However, this type of study is no longer feasible in a prospective manner because untreated control groups can no longer be ethically included. The use of archived material, in the 
present study, and discussed previously [25], can be very useful in spite of the drawbacks of lack of samples from randomized clinical trials.

Taking the above-described considerations into account, in this study we report for the first time that the 76-gene prognostic signature not only can classify breast cancer patients into high- and low-risk disease recurrence groups, but may also predict which breast cancer patients will benefit from adjuvant tamoxifen therapy. High-risk patients classified by the 76-gene signature had a significant $12.3 \%$ absolute benefit from tamoxifen therapy, while the predicted low-risk patients only had a (non-significant) $2.7 \%$ absolute benefit from tamoxifen. This suggests that the high-risk patients classified by the 76-gene signature benefit substantially from adjuvant tamoxifen. Whether and to what extent these patients would benefit from additional chemotherapy or from the incorporation of new endocrine strategies i.e., with aromatase inhibitors in the therapy remains to be evaluated. Of note, the patients falling in the low-risk category as identified by the 76-gene signature have such an excellent prognosis on tamoxifen alone that the use of adjuvant chemotherapy would be difficult to justify. The prognosis of this group of these low-risk patients is sufficiently good, in fact, that it would be difficult to demonstrate an improvement in DMFS by tamoxifen in this group. Other potential benefits from adjuvant endocrine therapy, such as prevention of loco-regional relapse or contralateral breast cancer need to be weighed against potential side effects in each individual patient.

In conclusion, these results support the conclusion that the use of the 76-gene signature could refine clinical decision making on endocrine therapy in the clinic. We have demonstrated in this study that the 76-gene signature is not only predictive for disease recurrence, but also predicts benefit of tamoxifen in LNN/ER+ breast cancer patients. The benefit was not equally strong in the different risk-groups identified by the 76-gene prognostic signature, but was confined to the high-risk patients. This supports our previous assertion that the predicted low-risk patients might be spared the burden of unnecessary (additional) chemotherapy [17], and that even endocrine therapy might not be needed in all such cases.

Acknowledgments We thank Mieke Timmermans, Anita TrapmanJansen, Vanja de Weerd and Wendy van der Smissen for technical assistance, and Marion Meijer-van Gelder for handling of the clinical data. This study was supported in part by The Netherlands Genomics Initiative (NGI)/Netherlands Organization for Scientific Research (NWO).

\section{References}

1. Osborne CK, Yochmowitz MG, Knight WAIII, McGuire WL (1980) The value of estrogen and progesterone receptors in the treatment of breast cancer. Cancer 46:2884-2888. doi:10.1002/ 1097-0142(19801215)46:12+<2884::AID-CNCR2820461429>3. $0 . \mathrm{CO} ; 2-\mathrm{U}$

2. Fisher B, Dignam J, Bryant J, DeCillis A, Wickerham DL, Wolmark $\mathrm{N}$ et al (1996) Five versus more than five years of tamoxifen therapy for breast cancer patients with negative lymph nodes and estrogen receptor-positive tumors. J Natl Cancer Inst 88:1529-1542. doi:10.1093/jnci/88.21.1529

3. Fisher B, Jeong JH, Bryant J, Anderson S, Dignam J, Fisher ER et al (2004) Treatment of lymph-node-negative, oestrogen-receptor-positive breast cancer: long-term findings from National Surgical Adjuvant Breast and Bowel Project randomised clinical trials. Lancet 364:858-868. doi:10.1016/S0140-6736(04)16981-X

4. Perou CM, Sorlie T, Eisen MB, van de Rijn M, Jeffrey SS, Rees CA et al (2000) Molecular portraits of human breast tumours. Nature 406:747-752. doi:10.1038/35021093

5. Sorlie T, Perou CM, Tibshirani R, Aas T, Geisler S, Johnsen H et al (2001) Gene expression patterns of breast carcinomas distinguish tumor subclasses with clinical implications. Proc Natl Acad Sci USA 98:10869-10874. doi:10.1073/pnas.191367098

6. Gruvberger S, Ringner M, Chen Y, Panavally S, Saal LH, Borg A et al (2001) Estrogen receptor status in breast cancer is associated with remarkably distinct gene expression patterns. Cancer Res 61:5979-5984

7. Hedenfalk I, Duggan D, Chen Y, Radmacher M, Bittner M, Simon R et al (2001) Gene-expression profiles in hereditary breast cancer. N Engl J Med 344:539-548. doi:10.1056/NEJM 200102223440801

8. Van 't Veer LJ, Dai H, van de Vijver MJ, He YD, Hart AA, Mao M et al (2002) Gene expression profiling predicts clinical outcome of breast cancer. Nature 415:530-536. doi:10.1038/415530a

9. Wang Y, Klijn JG, Zhang Y, Sieuwerts AM, Look MP, Yang F et al (2005) Gene-expression profiles to predict distant metastasis of lymph-node-negative primary breast cancer. Lancet 365:671-679

10. Ma XJ, Wang Z, Ryan PD, Isakoff SJ, Barmettler A, Fuller A et al (2004) A two-gene expression ratio predicts clinical outcome in breast cancer patients treated with tamoxifen. Cancer Cell 5:607-616. doi:10.1016/j.ccr.2004.05.015

11. Sotiriou C, Wirapati P, Loi S, Harris A, Fox S, Smeds J et al (2006) Gene expression profiling in breast cancer: understanding the molecular basis of histologic grade to improve prognosis. J Natl Cancer Inst 98:262-272

12. Jansen MP, Foekens JA, van Staveren IL, Dirkzwager-Kiel MM, Ritstier K, Look MP et al (2005) Molecular classification of tamoxifen-resistant breast carcinomas by gene expression profiling. J Clin Oncol 23:732-740. doi:10.1200/JCO.2005.05.145

13. Hess KR, Anderson K, Symmans WF, Valero V, Ibrahim N, Mejia JA et al (2006) Pharmacogenomic predictor of sensitivity to preoperative chemotherapy with paclitaxel and fluorouracil, doxorubicin, and cyclophosphamide in breast cancer. J Clin Oncol 24:4236-4244. doi:10.1200/JCO.2006.05.6861

14. Potti A, Dressman HK, Bild A, Riedel RF, Chan G, Sayer R et al (2006) Genomic signatures to guide the use of chemotherapeutics. Nat Med 12:1294-1300. doi:10.1038/nm1491

15. Paik S, Shak S, Tang G, Kim C, Baker J, Cronin M et al (2004) A multigene assay to predict recurrence of tamoxifen-treated, nodenegative breast cancer. N Engl J Med 351:2817-2826. doi: 10.1056/NEJMoa041588

16. Paik S, Tang G, Shak S, Kim C, Baker J, Kim W et al (2006) Gene expression and benefit of chemotherapy in women with node-negative, estrogen receptor-positive breast cancer. J Clin Oncol 24:3726-3734. doi:10.1200/JCO.2005.04.7985

17. Foekens JA, Atkins D, Zhang Y, Sweep FC, Harbeck N, Paradiso A et al (2006) Multicenter validation of a gene expression-based prognostic signature in lymph node-negative primary breast cancer. J Clin Oncol 24:1665-1671. doi:10.1200/JCO.2005.03.9115 
18. Desmedt C, Piette F, Loi S, Wang Y, Lallemand F, Haibe-Kains B et al (2007) Strong time dependence of the 76-gene prognostic signature for node-negative breast cancer patients in the TRANSBIG multicenter independent validation series. Clin Cancer Res 13:3207-3214. doi:10.1158/1078-0432.CCR-06-2765

19. McShane LM, Altman DG, Sauerbrei W, Taube SE, Gion M, Clark GM (2006) REporting recommendations for tumor MARKer prognostic studies (REMARK). Breast Cancer Res Treat 100:229-235. doi:10.1007/s10549-006-9242-8

20. Lipshutz RJ, Fodor SP, Gingeras TR, Lockhart DJ (1999) High density synthetic oligonucleotide arrays. Nat Genet 21:20-24. doi: $10.1038 / 4447$

21. Kaplan EL, Meier P (1958) Non-parametric estimation from incomplete observations. J Am Stat Assoc 53:457-481. doi: $10.2307 / 2281868$

22. Harvell D, Spoelstra N, Singh M, McManaman J, Finlayson C, Phang T, et al (2008) Molecular signatures of neoadjuvant endocrine therapy for breast cancer: characteristics of response or intrinsic resistance. Breast Cancer Res Treat. doi: 10.1007/s 10549-008-9897-4 press)

23. Loi S, Haibe-Kains B, Desmedt C, Wirapati P, Lallemand F, Tutt AM et al (2008) Predicting prognosis using molecular profiling in estrogen receptor-positive breast cancer treated with tamoxifen. BMC Genomics 9:239

24. Gasparini G, Pozza F, Harris AL (1993) Evaluating the potential usefulness of new prognostic and predictive indicators in nodenegative breast cancer patients. J Natl Cancer Inst 85:1206-1219. doi:10.1093/jnci/85.15.1206

25. Harbeck N, Kates RE, Look MP, Meijer-Van Gelder ME, Klijn JG, Kruger A et al (2002) Enhanced benefit from adjuvant chemotherapy in breast cancer patients classified high-risk according to urokinase-type plasminogen activator (uPA) and plasminogen activator inhibitor type $1(n=3424)$. Cancer Res $62: 4617-4622$ 